\title{
Mutations in the Epstein-Barr virus latent membrane protein-1 (BNLF-1) gene in spontaneous lymphoblastoid cell lines: effect on in vitro transformation associated parameters and tumorigenicity in SCID and nude mice
}

\author{
Kristian Sandvej, Mette Munch, Stephen Hamilton-Dutoit
}

\begin{abstract}
Aims-(1) To study the frequency of putative malignancy associated point mutations and a 30 base pair (bp) deletion in exon 3 of the C-terminus of the EpsteinBarr virus (EBV) encoded latent membrane protein (LMP)-1 (BNLF-1) gene in wild type EBV strains. (2) To assess the influence of these mutations on the tumorigenicity of lymphoblastoid cell lines (LCL).

Methods-Eight spontaneous EBV (wild type) infected LCL were established from seven subjects. Deletions and single base mutations in the C-terminus of the BNLF-1 gene were demonstrated using bi-directional solid phase dideoxy sequencing following PCR amplification of viral DNA from the LCL. Tumorigenicity of the LCL was assessed in SCID and nude mice. Serum dependent growth and ability to form colonies in soft agarose were assessed for representative $L C L$.

Results-All LCL showed sequence differences compared with the prototypic EBV

strain B95-8. The 30 bp deletion could be detected in three of eight LCL and a 69 bp deletion (including the $30 \mathrm{bp}$ deletion) was identified in an additional LCL. A range of single base mutations (including those described previously in association with EBV related neoplasias) was also seen in some of the LCL. In transformation studies, the genetic variations did not seem to influence the in vitro behaviour of the LCL. In the tumorigenicity studies, the presence of the $30 \mathrm{bp}$ deletion had no influence on the behaviour of the LCL which were, as expected, tumorigenic in SCID mice but not in nude mice. In contrast, the LCL carrying the 69 bp deletion was tumorigenic in both SCID and nude mice.

Conclusions-Genetic changes described previously in the C-terminus of the LMP-1 gene in various malignancy derived EBV strains are also present frequently in wild type viruses and do not simply define tumour specific EBV strains. Changes within this region may, however, still be important for the tumorigenicity of LMP-1 and thus play a role in EBV oncogenesis.

(F Clin Pathol: Mol Pathol 1996;49:M290-M297)
\end{abstract}

Laboratory of Immunopathology, University Institute of Pathology, Aarhus Kommunehospital, Aarhus, Denmark K Sandvej

S Hamilton-Dutoit

Centre for Medical Molecular Biology, Aarhus University Hospital and Faculty of Health Science, Skejby Sygehus, Denmark K Sandvej

Department of Medical Microbiology and Immunology, University of Aarhus, Aarhus C, Denmark $M$ Munch

Correspondence to: Dr K Sandvej, Laboratory of Immunopathology, University Institute of Pathology, Aarhus Kommunehospital, Finsensgade 12, DK-8000 Aarhus C, Denmark.

Accepted for publication 9 July 1996
Keywords: Epstein-Barr virus, latent membrane protein-1, spontaneous lymphoblastoid cell lines.

Epstein-Barr virus (EBV) is a human herpes virus that causes infectious mononucleosis and is associated with various malignancies, including nasopharyngeal carcinoma, Burkitt's lymphoma, Hodgkin's disease, peripheral $\mathrm{T}$ cell lymphomas, and lymphoproliferative disorders in immunosuppressed patients. ${ }^{2-7}$

In vitro, EBV transformed lymphoblastoid cell lines (LCL) can be established by spontaneous outgrowth of EBV infected B cells from the peripheral blood of seropositive subjects. ${ }^{8}$ LCL consistently display a restricted pattern of EBV gene products (recently designated latency type III), characterised by the expression of EBV nuclear antigen (EBNA)-1, EBNA-2, EBNA-3a, b and $c$, and EBNA-LP, latent membrane protein (LMP)-1 and LMP2a/b, and EBV small nuclear RNAs (EBERs) $-1 / 2 .{ }^{9}$ LMP-1 plays an important part in EBV induced cell transformation. Among other things, it is essential for the transformation of primary B cells, ${ }^{10}$ it can transform rodent fibroblasts and human keratinocytes, ${ }^{11}{ }^{12}$ inhibit human epithelial cell differentiation, ${ }^{13}$ and it is toxic to cells when expressed at high concentrations. ${ }^{14}{ }^{15}$ In transgenic mice LMP-1 induces hyperplastic dermatitis and abnormal keratin expression. ${ }^{16}$ LMP-1 induces DNA synthesis ${ }^{17}$ and upregulates expression of several lymphocytic activation markers and adhesion molecules. ${ }^{18}$

Recently, $\mathrm{Hu}$ et $a l^{19}$ demonstrated several mutations in the gene, BNLF-1, encoding LMP-1 in nude mouse propagated Chinese nasopharyngeal carcinoma (CAO) cells compared with the prototype EBV strain B95-8 (ECACC no. 85011419). Subsequently, it has been suggested that these BNLF-1 gene mutations characterise an EBV strain in Asia, which is associated preferentially with nasopharyngeal carcinoma. ${ }^{20}$ Tumorigenicity studies on SCID and nude mice indicated that the CAO LMP-1 was more tumorigenic than B95-8LMP $-1 .{ }^{2021}$

Analysis of the CAO BNLF-1 gene has revealed a 30 base pair (bp) deletion and seven single base mutations in the $\mathrm{C}$-terminal region, between the coding triplets for amino acids 322 and 366 of exon $3{ }^{19}$ In a recent study of EBV positive lymphomas we found the $30 \mathrm{bp}$ 
deletion and six of the seven single base mutations in all peripheral $\mathrm{T}$ cell lymphomas from Malaysian patients, in about $60 \%$ of peripheral $\mathrm{T}$ cell lymphomas from Danish patients and in about $30 \%$ of cases of Hodgkin's disease and infectious mononucleosis. ${ }^{22}$ The mutations were detected in both EBV subtypes A and B, and the single base mutations and the $30 \mathrm{bp}$ deletion occurred independently in some cases. In addition, we detected a 12 bp deletion consisting of 12 of the nucleotides of the $30 \mathrm{bp}$ deletion in one case of Hodgkin's disease. These findings indicate that mutations in the C-terminal part of the BNLF-1 gene are not associated specifically with either Asian nasopharyngeal carcinoma or EBV subtype A, although they do seem to be more common in Asia than in the West. Rather, the $30 \mathrm{bp}$ deletion and some of the sites of single base mutation may be hot spots which have mutated independently throughout the evolution of EBV strains. Similar findings have been reported independently from other laboratories. $^{2324}$

The apparent convergent evolution of EBV strains of both subtype A and B from different geographical locations suggests that these mutations impart some advantage to the virus. In vitro studies by Moorthy and ThorleyLawson showed that the C-terminal part of LMP-1 is essential for transformation. ${ }^{15}{ }^{25}$ Furthermore, their results indicated that the absence of the amino acid sequence between positions 334 and 364 generated a toxic LMP-1 protein, suggesting that this amino acid sequence is essential for the normal function of the protein. The $30 \mathrm{bp}$ deletion is located within this sequence and may therefore affect the function of the LMP-1 protein. This is supported by recent findings from $\mathrm{Li}$ et al. ${ }^{26}$ Their transfection study on Balb/3T3 cells showed that introduction of the $30 \mathrm{bp}$ deletion into the B95.8 BNLF-1 gene made these cells tumorigenic in nude mice. In the present study we have sequenced the C-terminal part of the EBV-BNLF-1 gene in eight spontaneously established LCL and identified wild type EBV strains that display various mutations within this region. The effect of these mutations on LCL transformation related parameters in vitro and LCL tumorigenicity in SCID and nude mice in vivo was investigated.

\section{Methods}

ESTABLISHMENT OF LCL

As part of a separate study, LCL were established with cells from six patients with multiple sclerosis and from one blood donor. Two separate LCL were established (with a 42 day interval) from cells from one of the patients. In each case, $50 \mathrm{ml}$ of venous blood was drawn into Venoject tubes. Heparinised blood was diluted 1 in 2 in phosphate buffered saline (PBS)/heparin (PBS pH 7.4, $20 \mathrm{IU} / \mathrm{ml}$ heparin), before separating the mononuclear cells by Ficoll-Isopaque density gradient centrifugation. The mononuclear cell layer was isolated and washed in PBS and subsequently in RPMI 1640 (BioWhittaker, Walkersville, Maryland, USA). The cells were then counted and seeded at densities between $2 \times 10^{6} / \mathrm{ml}$ and $4 \times 10^{6} / \mathrm{ml}$ in $5 \mathrm{ml}$ growth medium, which, on day 3, was adjusted to $10 \mathrm{ml}$. Growth medium consisted of RPMI 1640 supplemented with $200 \mathrm{IU} / \mathrm{ml}$ penicillin (Leo, Ballerup, Denmark), $0.2 \mathrm{mg} / \mathrm{ml}$ streptomycin (Sigma, St Louis, Missouri, USA), $0.29 \mathrm{mg} / \mathrm{ml}$ glutamin (Sigma), 0.01M HEPES buffer (BioWhittaker), and $10 \%$ heat inactivated human serum in Falcon Primaria bottles $(50 \mathrm{ml})$. For each patient there were at least two mononuclear cell cultures, with and without $0.1 \mu \mathrm{g} / \mathrm{ml}$ cyclosporin A (Sandoz, Basel, Switzerland). The cyclosporin A was maintained in the medium for five weeks by regular refeeding. Half of the supernatant medium was changed three times weekly until a LCL was established or all cells were dead. LCL appeared after 60 to 180 days. Cultures were then split every two to three days and reseeded at a concentration of $5 \times 10^{5} / \mathrm{ml}$.

\section{GENETIC FINGERPRINTING}

To test for cross contamination of the LCL, typing of DNA from each LCL culture was performed. The DNA was purified according to standard methods from mononuclear cells isolated on the day of blood sampling and from LCL. Restriction fragment length polymorphisms (RFLPs) of variable numbers of tandem repeat (VNTR) regions were investigated. ${ }^{27-30}$ HLA-DQ $\alpha$ typing was performed on PCR amplified DNA with the AmpliType kit (Roche, USA).

\section{CYTOGENETICS}

Apart from the following modifications, flow cytometry analysis was performed as described previously. ${ }^{31}$ After washing twice in PBS, the cells were resuspended in $2 \mathrm{ml}$ staining solution containing $10 \mathrm{mM}$ Tris- $\mathrm{HCl}, 80 \mathrm{mM}$ $\mathrm{KCl}, 20 \mathrm{mM} \mathrm{NaCl}, 3.4 \mathrm{mM}$ sodium citrate, $10 \mathrm{mM} \mathrm{MgCl}_{2}, 0.5 \mathrm{mM}$ EDTA, $0.5 \mathrm{mM}$ Spermine, $0.5 \mathrm{mM}$ Spermidine, $0.1 \%$ Nonidet $\mathrm{P} 40, \mathrm{pH} \mathrm{7.6}$, and propidiurn iodide (PI) to a final concentration of $100 \mu \mathrm{l} \mathrm{PI} / \mathrm{ml}$. The staining/lysis time was 10-15 minutes. A normal diploid reference was superimposed on the expected normal diploid peak in the histogram. The DNA profile was analysed on a FACStar Plus analyser (Becton Dickinson, Burlingame, California, USA).

\section{TUMORIGENICITY}

Female SCID and nu/nu mice of NMRI background were obtained from Bomholtgaard Animal Breeding and Research Centre, Ry, Denmark, and kept under conventional conditions during the experiments. The mice were seven to eight weeks old, with five to 10 mice of each kind being used for each cell line. Suspensions of $5.5 \times 10^{6}$ cells in $200 \mu \mathrm{l} 0.9 \%$ $\mathrm{NaCl}$ were inoculated subcutaneously in the left flank. The mice were inspected weekly for the appearance and progressive growth of tumours. Tumour tissue was snap frozen and stored at $-80^{\circ} \mathrm{C}$. Animals without tumours were kept for 26 weeks. 
IMMUNOHISTOLOGY

Cell pellets from cell cultures and tumour tissue from SCID and nude mice were snap frozen. Sections were cut and stained using APAAP immunohistology. The LCL from both cultures and tumours were characterised as $\mathrm{B}$ cells using monoclonal antibodies directed against CD19, CD20 and CD21. The sections were also stained for activation markers intracellular adhesion molecule-1 (ICAM-1) (CD54), LFA-3 (CD58) and CD23, and for bcl-2. Expression of EBV gene products was demonstrated using the monoclonal antibodies PE2 (EBNA-2), CS.1-4 (LMP-1) and BZ1 (BZLF-1 protein), as described previously. ${ }^{32}$

SAMPLE PREPARATION FOR PCR

Five $10 \mu \mathrm{m}$ frozen sections were cut from the mouse tumours and placed in an Eppendorf tube using disposable Pasteur pipettes. Before and after cutting sections for PCR, histological control sections were cut and stained with haematoxylin to demonstrate the presence of tumour cells. Between cases the cryostat was cleaned with $70 \%$ alcohol and for each case a new knife was used. For every tumour two tubes with sections from a pellet consisting only of Tissue-Tek cryostat embedding medium (Miles, Elkhart, Indiana, USA) were cut as negative controls of the sectioning procedure. For PCR on cell lines, $10^{6}$ cells were spun down directly from cultures. Both sections and cell pellets were digested in $250 \mu$ l proteinase $\mathrm{K}$ $(200 \mu \mathrm{g} / \mathrm{ml})$ for 48 hours at $56^{\circ} \mathrm{C}$. The proteinase was inactivated by heating to $98^{\circ} \mathrm{C}$ for 15 minutes. The remains of the tissue was spun down briefly and the supernatant was used for PCR.

PCR

PCR was carried out in an automated thermal cycler (Perkin Elmer, Cetus, Norwalk, USA). All primers were synthesised by DNA Technology (Aarhus, Denmark). For EBNA-2 typing a single step PCR procedure was used. Primers flanking a $115 \mathrm{bp}$ deletion in the $\mathrm{U} 2$ region encoding EBNA-2A gave rise to a $378 \mathrm{bp}$ product from EBNA-2A EBV strains and a 483 bp product from EBNA-2B strains. ${ }^{33}$ EBV cell lines B95.8 and AG876 carrying EBNA-2A and EBNA-2B, respectively, were used as controls. ${ }^{34}$ To test for deletions in the C-terminus of the BNLF-1 gene, a PCR product was amplified from nucleotide positions 168390 to 168074 , according to Hudson et al..$^{35}$ Hodgkin's disease cases and the cell line AG 876 previously shown to contain the BNLF-1 30 bp deletion, and Hodgkin's disease cases and the cell line B95.8 shown not to contain deletions, were used as positive and negative controls, respectively. ${ }^{22}$ PCR was carried out in a $50 \mu \mathrm{l}$ reaction mixture $(3.75$ $\mathrm{mM} \mathrm{MgCl}$ and 5 units of AmpliTaq polymerase Stoffel fragment (Perkin Elmer Cetus)). Primers and PCR conditions have been described in detail elsewhere. ${ }^{22}{ }^{36}$ The size of the PCR product was verified after electrophoresis in Visigel separation matrix (Stratagene, La Jolla, California, USA) stained with ethidium bromide.
BI-DIRECTIONAL SOLID PHASE DIDEOXY

SEQUENCING

Sequence analysis was performed to demonstrate the size and the location of deletions, and to detect single base mutations, as described recently. ${ }^{22}$ Briefly, in all cases two parallel PCRs were performed, one for sequencing the sense strand and one for sequencing the antisense strand. The PCR product for sequencing the sense strand was produced with a nonbiotinylated sense primer and a 5' biotinylated antisense primer. The product for sequencing the antisense strand was produced with a nonbiotinylated antisense primer and a 5 ' biotinylated sense primer (the same primers as used to amplify the PCR product). After PCR the amplified fragments were captured from 35-50 $\mu \mathrm{l}$ of the reaction mix (the amount needed for sequencing was estimated by electrophoresis), with $30 \mu$ l Streptavidin conjugated magnetic beads (Dynabeads, Dynal, Norway), according to the manufacturer's instructions. After several washing steps the double stranded PCR product was denatured by incubating with $20 \mu \mathrm{l} 0.1 \mathrm{M} \mathrm{NaOH}$ for four minutes at room temperature. The supernatant containing the PCR product generated by the non-biotinylated primer was removed. The Dynabeads/single stranded DNA complex was washed once in $250 \mathrm{mM}$ Tris $(\mathrm{pH} 8) / 0.1 \%$ Tween 20, once in TE buffer and once in double distilled water, and resuspended in $10 \mu \mathrm{l}$ double distilled water. The sequencing reaction was carried out according to the manufacturer's instructions (PRISM Sequenase Terminator Single-Stranded DNA Sequencing Kit, Applied Biosystems Inc., Foster City, California, USA), using fluorescence labelled dideoxynucleotide terminators as described. ${ }^{22}$ The gel was electrophoresed for 14 hours on a semiautomated ABI 373A sequencer (Applied Biosystems), and the results were analysed using the Seg Ed software program (Applied Biosystems).

\section{ANALYSIS OF SERUM DEPENDENT GROWTH}

Representative LCL with a 30 bp deletion (MS1845), with a 69 bp deletion (MS1859) and with no deletion (MS1851 and MS1858) in the C-terminal region of the LMP-1 molecule were used for analysis of growth and survival at different serum concentrations. Cells were seeded in triplicate at a starting density of $0.4 \times 10^{6}$ cells per ml (day 1 ) in $10 \mathrm{ml}$ growth medium with either $0.1 \%, 1.0 \%$ or $10 \%$ human serum. The number of viable cells was counted daily using the trypan blue exclusion test.

COLONY FORMATION IN SOFT AGAROSE

Seaplaque agarose (BioWhittaker) was dissolved in distilled water. A base layer of $0.3 \%$ agarose in $1.5 \mathrm{ml}$ RPMI 1640 supplemented with $200 \mathrm{IU} / \mathrm{ml}$ penicillin (Leo), $0.2 \mathrm{mg} / \mathrm{ml}$ streptomycin (Sigma), $0.29 \mathrm{mg} / \mathrm{ml}$ glutamin (Sigma), $0.01 \mathrm{M}$ HEPES buffer (BioWhittaker), and $10 \%$ heat inactivated human serum was poured into six-well multidishes (Nunc, Roskilde, Denmark). 


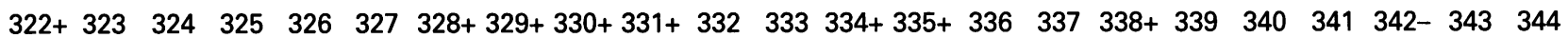
B95.8 CAA TTG ACG GAA GAG GTT GAA AAC AAA GGA GGT GAC CAG GGC CCG CCT TTG ATG ACA GAC GGA GGC GGC

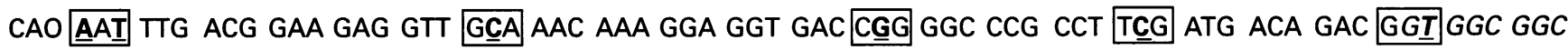
1851 CAA TTG ACG GAA GAG GTT CAA AAC AAA GGA GGT GAC CAG GGC CCG CCT TTG ATG ACA GAC GGA GGC GGC 1874 CAA TTG ACG GAA GAG GTT CAA AAC AAA GGA GGT GAC CAG GGC CCG CCT TTG ATG ACA GAC GGA GGC GGC 1844 CAA TTG ACG GAA GAG GTT CAA AAC AAA GGA GGT GAC CAG GGC CCG CCT TTG ATG ACA GAC GGA GGC GGC 1858 GAA TTG ACG GAA GAG GTT GAA AAC AAA GGA GGT GAC CGG GGC CCG CCT TCG ATG ACA GAC GGI GGC GGC

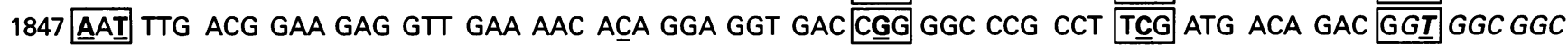
1845 AAT TTG ACG GAA GAG GTT GAA AAC AAA GGA GGT GAC CGG AGC CCG CCT T므 ATG ACA GAC GGI GGC GGC 1533 AAT TTG ACG GAA GAG GTT GAA AAC ACA GGA GGT GAC CGG GGC CCG CCT T므 ATG ACA GAC GGI GGC GGC

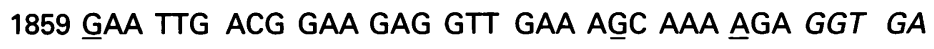

$\begin{array}{lllllllllllllllllllll}345 & 346 & 347 & 348 & 349 & 350 & 351 & 352+ & 353 & 354 & 355 & 356-357 & 358 & 359 & 360 & 361-362 & 363 & 364 & 365 & 366+\end{array}$ B95.8 GGT CAT AGT CAT GAT TCC GGC CAT GGC GGC GGT GAT CCA CAC CTT CCT ACG CTG CTT TTG GGT TCT CAO GGT GAT CCA CAC CTT CCT ACG CTG CTT TTG GGT ACT 1851 GGT CAT AGT CAT GAT TCC GGC CAT GGC GGC GGT GAC CCA CAC CTT CCT ACG CTG CTT TTG GGT ACT 1874 GGT CAT AGT CAT GAT TCC GGC CAT GGC GGC GGT GAC CCA CAC CTT CCT ACG CTG CTT TTG GGT ACT 1844 GGT CAT AGT CAT GAT TCC GGC CAT GGC GGC GGT GAC CCA CAC CTT CCT ACG CTG CTT TTG GGT ACT 1858 GGT CAT AGT CAT GAT TCC GGC CGT GGC GGC GGT GAT CCA CAC CTT CCT ACA CTG CTT TTG GGT ACT 1847 GGT 1845 GGT 1533 GGT 1859 GAT CCA CAC CTT CCT ACG CTG CTT TTG GGT ACT GAT CCA CAC CTT CCT ACG CTG CTT TTG GGT ACT GAT CCA CAC CTT CCT ACG CTG CTT TTG GGT ACT T CCA CAC CTT CCT ACA CTG CTT TTG GGT GCT

Figure 1 Sequence analysis of the C-terminal region of the EBV BNLF-1 gene which encodes LMP-1. Single base mutations identical with those found in the CAO BNLF-1 sequence are underlined and in bold. Single base mutations differing from both the B95.8 and CAO BNLF-1 gene are underlined. Amino acid changes identical with those found in the CAO LMP-1 protein are indicated by framing the coding triplet. The 5 bp and the 11 bp repeat sequences which could be implicated in the generation of the $30 \mathrm{bp}$ and $69 \mathrm{bp}$ deletions, respectively, are in italics. + indicates that the single base mutation affects the amino acid sequence; - indicates that the single base mutation does not affect the amino acid sequence.

The top layer was either $0.2 \%, 0.3 \%, 0.45 \%$, or $0.6 \%$ agarose in $1.5 \mathrm{ml}$ of the same medium as used for the base layer; 3000 cells were added per well from one of the following cell lines: MS1845, MS1851, MS1858 or MS1859. After setting, the agarose was covered with $1 \mathrm{ml}$ medium. All culture dishes were incubated at $37^{\circ} \mathrm{C}$ in $5 \% \mathrm{CO}_{2}$. Three independent experiments were carried out and each cell line was plated in triplicate. A colony was defined as a cluster consisting of more than 10 cells.

\section{Results}

PCR

EBNA-2 type A was detected in all eight LCL and in the EBV subtype A control cell line B95.8. EBNA-2 B was only found in the EBV subtype B control cell line AG 876. Amplification of the C-terminal region of the BNLF-1 gene indicated the presence of a deletion in four of eight LCL. In three cases (MS1845, MS1847 and MS1533) gel electrophoresis indicated that the deletion was approximately $30 \mathrm{bp}$. In the fourth case (MS1859) it was larger. PCR control experiments on tumours from SCID and nude mice gave results identical with those found in the respective inoculated LCL.

\section{SEQUENCE ANALYSIS}

The results are summarised in fig 1 . In the three cases with electrophoretical evidence of a deletion around $30 \mathrm{bp}$, sequence analysis confirmed the size to be $30 \mathrm{bp}$. Examination of the sequence environment surrounding the $30 \mathrm{bp}$ deletion revealed two 9 bp repeats (GGCGGCGGT) coding for three Gly residues (amino acids 343 to 345 and amino acids 353 to 355$)$. We have proposed previously that the 30 bp deletion can be generated by slipped mispairing of direct repeats. ${ }^{22}$ The sequence analysis suggests that this has probably been preceded by a single base mutation in amino acid 342 (A to $\mathrm{T}$ ) giving two $10 \mathrm{bp}$ repeats (TGGCGGCGGT; third base of the coding triplet of amino acids 342 to 345 and third base of the coding triplet of amino acids 352 to 355), one of which is included in the $30 \mathrm{bp}$ deletion (fig 1). Indeed, one of the LCL without the deletion (MS1858) has this mutation at amino acid 342 . In addition, this cell line has a mutation in the coding triplet for amino acid 352 (A to G), giving two $11 \mathrm{bp}$ repeats adjacent to the $30 \mathrm{bp}$ deletion, a change that would further increase the likelihood of a deletion occurring by slipped mispairing. Thus, there is circumstantial evidence that both of these mutations may be present prior to the deletion of the $30 \mathrm{bp}$ sequence.

In the MS1859 LCL with electrophoretical evidence of a deletion larger than $30 \mathrm{bp}$, sequence analysis revealed a 69 bp deletion comprising the sequence of the $30 \mathrm{bp}$ deletion and a further $39 \mathrm{bp}$. The sequence environment of the $69 \mathrm{bp}$ deletion contains two five nucleotide repeats (GGTGA), one of which is included in the $69 \mathrm{bp}$ deletion (fig 1).

Six of the seven single base mutations detected in the CAO BNLF-1 gene between amino acids 322 and 388 were found in all 

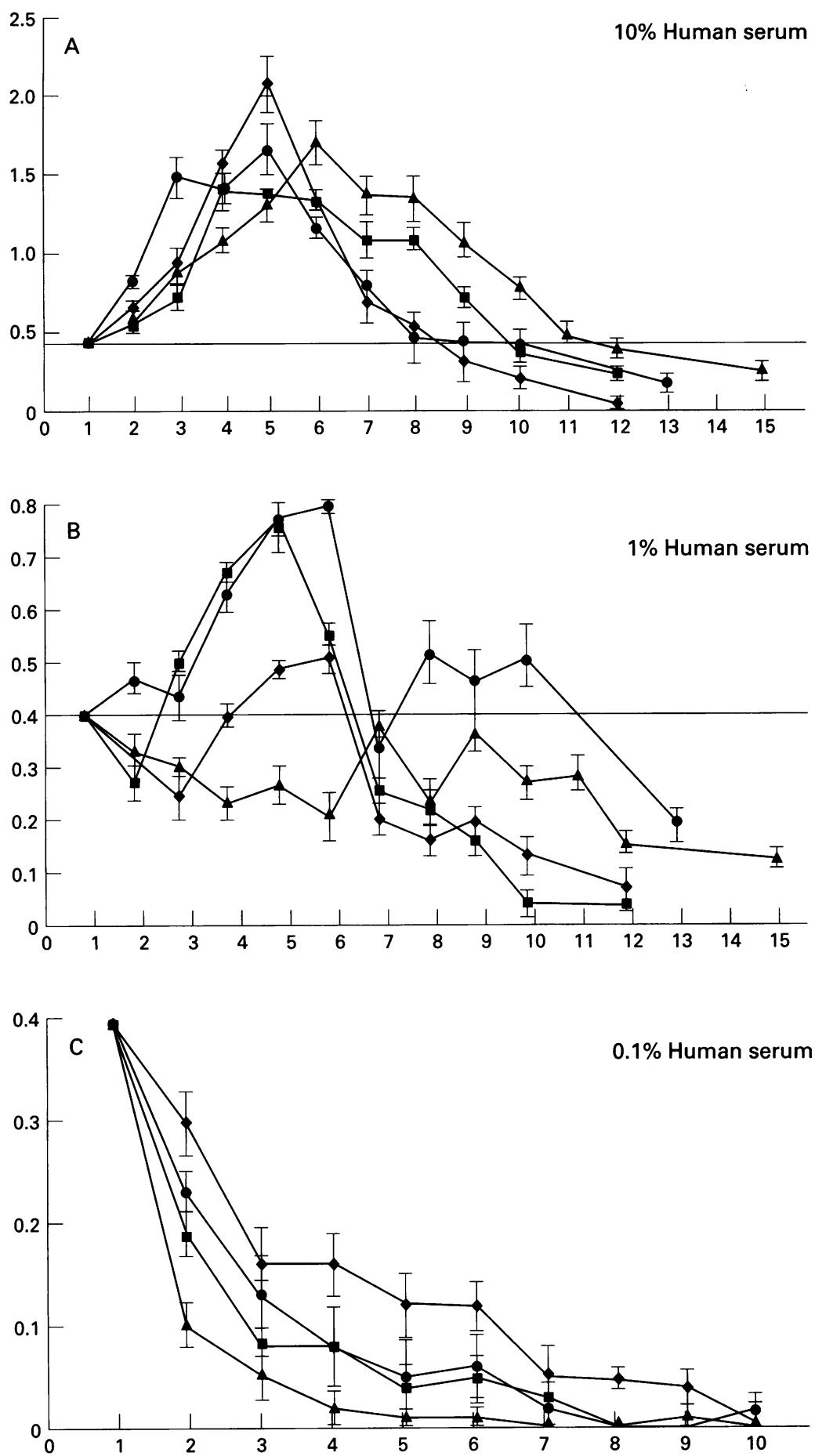

Figure 2 The ability of the cell lines MS1845, MS1851, MS1858, and MS1859 to survive in low serum concentrations was analysed by daily counts of viable cells. The serum concentrations $(0.1 \%, 1.0 \%$ and $10 \%$ human serum, respectively) are indicated on the graphs. The $y$-axis indicates the number of live cells/ml divided by $10^{6}$ and the $x$-axis the number of days in culture. Each LCL was cultured in triplicate. The curves represent the mean (SD). The labelling of the curves are as follows: $\square$, MS1845; , MS1851; MS1858; and $\triangle, M S 1859$. The horizontal line at $0.4 \times 10^{6}$ live cells/ml indicates the cell concentration at day 1.

three cases containing the $30 \mathrm{bp}$ deletion, the mutation affecting amino acid 328 being the one absent in all cases (fig 1). Two of these LCL (MS1847 and MS1533) had an additional mutation affecting amino acid 330 (A to C: Lys to Thr) and the third (MS1845), a mutation affecting amino acid 335 ( $G$ to A: Gly to Ser) (fig 1). The case with the $69 \mathrm{bp}$ deletion (MS1859) contained none of the single base mutations found in this region of the CAO BNLF-1 gene. However, single base mutations were demonstrated in the coding triplets of amino acids 322 (C to G: Gln to Glu), 329 (A to G: Asn to Ser), 331 (G to A: Gly to Arg), 356 ( $\mathrm{T}$ to $\mathrm{C}$ : no amino acid change), 361 ( $G$ to A: no amino acid change), and 366 ( $T$ to G: Ser to Ala) (fig 1).

Three of the LCL without deletions (MS1851, MS1874 and MS1844) showed a nucleotide sequence identical with B95.8 except for amino acid 328 (G to C: Glu to Gln) and amino acid 366 ( $\mathrm{T}$ to A: Ser to Thr). The fourth cell line (MS1858) contained mutations at amino acids 322 (C to G: Gln to Glu) and 352 (A to G: His to Arg) (fig 1), together with the single base mutations affecting amino acids $334,338,342$, and 366 detected in the CAO BNLF- 1 gene and in the three LCL with the $30 \mathrm{bp}$ deletion. In the sequence from amino acids 366 to 388 no single base mutations were detected in any of the LCL (data not shown).

GENETIC FINGERPRINTING

In all eight LCL individual genetic fingerprinting patterns were demonstrated excluding cross contamination with cells from flask to flask. Six of the eight virus isolates contained individual BNLF-1 sequences (see earlier) essentially ruling out virus cross contamination. The LCL MS1844 and MS1851 were identical in the sequenced part of the BNLF-1 gene, raising the possibility of identical EBV strains. These LCL were established independently and cultured at separate locations, strongly arguing against cross contamination.

TIME REQUIRED FOR LCL ESTABLISHMENT

Transformation of $\mathrm{B}$ lymphocytes leads to phenotypic changes and immortalisation. Development of LCL was characterised by free floating spherical or oval clusters of more or less tightly packed cells increasing in number over time. The time interval from seeding the mononuclear cell cultures to the appearence of LCL varied between 60 and 180 days. There was no correlation between the time taken to establish a LCL and the presence of the $30 \mathrm{bp}$ or the $69 \mathrm{bp}$ deletion in the BNLF-1 gene.

\section{SERUM DEPENDENT GROWTH}

The number of live cells as a function of days in culture is shown in fig 2 . There was no significant difference between the serum dependent growth of the cell lines. However, there was a tendency for a more serum dependent growth for the cell line MS1859 (containing the $69 \mathrm{bp}$ deletion), most clearly seen in the experiment with $1 \%$ human serum in the culture medium. The number of live cells in the MS1859 culture decreased after day 0 compared with the other cell lines which proliferated until about day 7. The same tendency was seen for MS1859 with $0.1 \%$ human serum where the cells died very quickly and with $10 \%$ human serum where the cell line proliferated more slowly and reached the maximum number of live cells later than for the other LCL.

\section{CLONING IN SOFT AGAROSE}

The ability to form colonies in soft agarose with low agarose concentrations $(0.2 \%$ and $0.3 \%$ ) was not associated with the presence of 
Table 1 Incidence of tumour formation by inoculation of lymphoblastoid cell lines subcutaneously in SCID and nude mice

\begin{tabular}{lll}
\hline Mouse type & Cell line & Tumour incidence \\
\hline SCID mice & MS1845 & 3 of 7 \\
& MS1851 & 4 of 5 \\
& MS1858 & 4 of 5 \\
Nude mice & MS1859 & 6 of 10 \\
& MS1845 & 0 of 5 \\
& MS1851 & 0 of 5 \\
& MS1858 & 0 of 5 \\
& MS1859 & 3 of 5 \\
\hline
\end{tabular}

mutations. Only the number of live and dead cells in the culture flasks counted before seeding in agarose influenced colony formation. A relatively high number of live cells (about $1 \times 10^{6}$ cells $/ \mathrm{ml}$ ) and a fraction of dead cells under 0.1 increased colony formation.

\section{TUMORIGENICITY}

The incidence of tumour formation in SCID and nude mice is shown in table 1 . Tumours were generated in SCID mice by all four cell lines tested (MS1845, MS1859, MS1851, and MS1858). Invasive growth into the skin resulting in necrotic ulcers was evident in two of four mice with tumour inoculated with the LCL MS1851 and MS1858, two of three mice with tumour inoculated with MS1845 and in five of six mice inoculated with MS1859. Tumours were generated in three of five nude mice inoculated with the LCL MS1859 (69 bp deletion) and grew non-invasively up to a size of $1 \mathrm{~cm}^{3}$ over the course of three to four weeks. Thereafter, the tumours regressed leaving a tumour of only $0.5 \mathrm{~cm}^{3}$ in two of the mice after 26 weeks, at which time the mice were sacrificed. In the third mouse no residual tumour was found. None of the nude mice inoculated with the other cell lines showed evidence of tumour formation over the 26 weeks of follow up.

\section{CYTOGENETICS}

The four cell lines used for tumorigenicity studies (MS1845, MS1859, MS1851, and MS1858) were all shown to be normal diploid cell lines by flow cytometry.

\section{IMMUNOHISTOLOGY}

All cell lines displayed characteristic LCL immunophenotype. No differences in the expression of the adhesion molecules ICAM-1 and LFA-3 or the activation marker CD23 could be demonstrated between cell lines with and without mutation of the BNLF-1 C-terminus. Comparable concentrations of EBV gene products EBNA-2, LMP-1 and BZLF-1 were detected in all LCL. The LMP-1 staining pattern indicated cytoplasmic and membrane staining with focal positivity, suggesting patching in the membrane. No differences in staining patterns between cell lines with and without mutations of the BNLF-1 C-terminus could be detected. Bcl-2 was expressed by all cell lines at comparable levels. SCID mice tumours displayed a staining pattern similar to LCL, except for CD21 and CD23 which were slightly down regulated in all tumours from SCID mice. In two tumours from nude mice EBNA-2 expression was demonstrated in the nuclei of tumour cells, confirming the presence of EBV infected lymphocytes rather than a non-specific reaction.

\section{Discussion}

Recent studies have shown that single base mutations and the $30 \mathrm{bp}$ deletion detected in the C-terminus of the CAO BNLF-1 gene can be detected frequently in EBV associated malignancy in vivo. ${ }^{22} 23637$ The CAO BNLF-1 isolate shows increased tumorigenicity in SCID and nude mice compared with prototypic EBV strains, and it has been suggested that mutant LMP-1 is preferentially associated with aggressive forms of EBV malignancy. ${ }^{36}$ The present study shows that similar genetic changes occur frequently in wild type EBV strains present in spontaneously arising LCL and do not by themselves characterise a tumour specific genotype. Clearly, care must be taken in interpreting the results of this study. Only viruses carrying LMP-1 capable of supporting transformation will be present in LCL. This selection bias means that the variants we have studied may not be completely representative of wild type viruses as a whole.

Recombinant EBV molecular genetic experiments with specifically mutated LMP-1 genes have demonstrated that LMP-1 is essential for LCL outgrowth. ${ }^{10}$ Our results indicate that neither the $30 \mathrm{bp}$ nor the $69 \mathrm{bp}$ deletions are essential for LMP-1 mediated primary B cell transformation. Furthermore, comparison of transformation related parameters indicated that the deletions did not affect the in vitro behaviour of the LCL significantly. However, there was a tendency for the LCL with the EBV strain containing the $69 \mathrm{bp}$ deletion to be more serum dependent than the other LCL.

It is tempting to ascribe the increased tumorigenicity of MS1859 to the $69 \mathrm{bp}$ LMP-1 deletion. Clearly, however, this may be because of changes elsewhere in the viral genome not identified by our analysis, and formal proof will require further transfection studies.

In vitro evidence that the $30 \mathrm{bp}$ deletion may still play a role in tumorigenesis has come from a recent study by $\mathrm{Li}$ et al. ${ }^{26}$ They found differences in the behaviour of Balb/3T3 cells when transfected with B95.8 BNLF-1 gene in which the $30 \mathrm{bp}$ sequence had been deleted, compared with the prototypic B95.8 BNLF-1 gene. The transfected cells became tumorigenic in nude mice, the transforming capacity of the virus increased, and the gene was toxic to the cells at lower expression levels compared with the wild type B95.8 BNLF-1 gene. The apparent discrepancies between this study and our findings may be partly due to differences in the behaviour of the BNLF-1 gene in rodent compared with human cell lines, as has been described in other circumstances. ${ }^{38}$

Alternatively, failure to detect an effect of the $30 \mathrm{bp}$ deletion may be because of a lack of sensitivity in our assay. In any event, the results of our study and those of $\mathrm{Li}$ et $a l^{26}$ suggest that the 
sequences of the $30 \mathrm{bp}$ and $69 \mathrm{bp}$ deletions may have an important role in LMP-1 protein function.

Recent studies by Moorthy and ThorleyLawson may offer an explanation for the apparent increased tumorigenicity of EBV variants with the 30 and $69 \mathrm{bp}$ deletions in Balb/3T3 cells and in our LCL, respectively. They showed that deleting $23(\Delta 364-386)$ or 81 amino acids $(\Delta 306-386)$ from the C-terminus resulted in a LMP-1 protein that was non-transforming, but turned over normally in Rat-1 fibroblasts. In contrast, deleting $64(\Delta 323-386)$ or $53(\Delta 334-386)$ amino acids from the C-terminus generated toxic LMP-1 mutants, suggesting that the toxicity was caused by the absence of the amino acid sequence 334-364..$^{15}$ The 69 bp deletion described by us constitutes about two thirds of this amino acid sequence. Thus, the toxicity in Rat- 1 cells and the increased tumorigenicity of LCL may be caused by similar changes in function of the LMP-1 protein. The $30 \mathrm{bp}$ deletion variant has lost about one third of the 334-364 amino acid sequence, and this may account for its increased toxicity in Balb/3T3 cells $^{26}$ when driven by a weaker promoter compared with the B95.8 BNLF-1 gene. Trivedi et $a l^{\beta 9}$ have shown that the LMP-1 protein encoded by the CAO BNLF-1 gene (which contains the $30 \mathrm{bp}$ deletion) is less immunogenic than B95.8 LMP-1. This offers a possible explanation for the increased tumorigenicity of variants lacking the $30 \mathrm{bp}$ and $69 \mathrm{bp}$ sequences, although it cannot account for the increased transforming capacity of the $30 \mathrm{bp}$ deletion variant found by $\mathrm{Li}$ et al compared with B95.8. ${ }^{26}$ LMP-1 has been shown to induce the expression of bcl-2 in B cells and this response was found to be delayed relative to NF- $\mathrm{KB}$ activation, suggesting that NF- $\kappa \mathrm{B}$ might mediate this response. ${ }^{40}$ The $30 \mathrm{bp}$ and the $69 \mathrm{bp}$ deletions are located close to or possibly overlap the NF- $\mathrm{KB}$ activation region of LMP $-1,{ }^{38}$ suggesting that the bcl-2 response of LMP-1 expression could be affected by the deletions. However, we found no immunohistological evidence for this.

The $69 \mathrm{bp}$ deletion is rare in vivo, having been demonstrated previously in only one AIDS related lymphoma, in one case of chronic lymphoproliferative disease in a child, and in a single case of Hodgkin's disease in a Liberian patient but in none of some 100 European Hodgkin's disease cases investigated. ${ }^{22}{ }^{36}$ We have previously proposed that the 30 bp deletion can be generated by slipped mispairing of direct repeats. ${ }^{22}$ If a similar mechanism is responsible for the $69 \mathrm{bp}$ deletion, then the relative rarity of this variation compared with the $30 \mathrm{bp}$ deletion may simply be explained by the size of the deletion and the direct repeats. The direct repeats present in the sequence environment of the $30 \mathrm{bp}$ and the $69 \mathrm{bp}$ deletions are of $11 \mathrm{bp}$ and $5 \mathrm{bp}$, respectively. The frequency of slipped mispairing has been shown to be proportional both to the length of the direct repeat motif and to the extent of homology between the direct repeats, but inversely proportional to the distance between them. ${ }^{41}$ As a consequence of this the $69 \mathrm{bp}$ deletion should be generated much less frequently than the $30 \mathrm{bp}$ deletion.

In conclusion, these results and our recently published data on Hodgkin's disease, peripheral $\mathrm{T}$ cell lymphoma and infectious mononucleosis show that mutations in the C-terminal region of the BNLF-1 gene occur frequently in both malignant and benign EBV infected cells and are more widespread among wild type EBV strains than originally thought. ${ }^{22}$ While these mutations clearly do not simply define tumour specific EBV strains, our study suggests that the LMP-1 amino acid sequence 334-356 (or part of this sequence) is of importance for the tumorigenic effects of LMP-1, and that changes in the function of LMP1 may result in altered tumorigenicity of EBV infected LCL. Studies on larger numbers of LCL from normal EBV seropositive subjects are needed to investigate which mutations occur regularly in the BNLF-1 gene. Further mutational studies in vitro are needed to define the effect of the $69 \mathrm{bp}$ deletion described in this study.

This work was supported by the Danish Cancer Society grant 95 120-01 and the Danish Multiple Sclerosis Society.

We wish to thank Niels Gregersen and Brage Andresen from the Centre for Medical Molecular Biology, University Hospital of Aarhus, for assistance with sequence analysis, Professor Lars Bolund, Institute of Medical Genetics, University of Aarhus, for assistance with the flow cytometry analyses, and Professor Søren Mogensen, Department of Medical Microbiology and Immunology, University of Aarhus, for critical review of the Immunology, University of Aarhus, for critical review of the manuscript. We also wish to thank Tom Nordfelt, Marianne
Rasmussen, Margit Schjerven, Inga Knudsen, and Margrethe Rasmussen, Margit Schjerven, Inga Knud
Kjeldsen for excellent technical assistance.

1 Henle G, Henle W, Diehl V. Relation of Burkitt's tumour-associated herpes-type virus to infectious mononucleosis. Proc Natl Acad Sci USA 1968;59:94-101.

2 Zur Hausen H, Schulte-Holthausen H, Klein G, Henle W, Henle G, Clifford P, et al. EBV DNA in biopsies of Burkitt's lymphoma and anaplastic carcinoma of the nasopharynx. Nature 1970;228:1056-8.

3 Young L, Dawson C, Clark D, Rupani H, Busson P, Turz T, et al. Epstein-Barr virus gene expression in nasopharyngeal carcinoma. $f$ Gen Virol 1988;69:1051-65.

4 Pallesen G, Hamilton-Dutoit SJ, Rowe M, Young L. Expression of Epstein-Barr virus latent gene products in tumour cells of Hodgkin's disease. Lancet 1991;ii:320-2.

5 Pallesen G, Hamilton-Dutoit SJ, Zhou XG. The association of Epstein-Barr virus (EBV) with T cell lymphoproliferaof Epstein-Barr virus (EBV) with T cell lymphoproliferation and Hodgkin's disease: Two new develop
EBV field. Adv Cancer Res 1993;62:179-239.

6 Hanto DW, Gajl-Peczalska KJ, Frizzera G, Arthur DC, Balfour $\mathrm{HH}$, McClain $\mathrm{K}$, et al. Epstein-Barr virus (EBV) induced polyclonal and monoclonal B-cell lymphoproliferative disease occurring after renal transplantation. Clinical pathological, and virological findings and implications for therapy. Ann Surg 1983;198:356-69.

7 Hamilton-Dutoit SJ, Pallesen G, Franzmann MB, Karkov J, Black F, Skinhøj P, et al. AIDS related lymphomas. Histopathology, immunophenotype and association with Epstein-Barr virus as demonstrated by in situ nucleic acid hybridisation. Am F Pathol 1991;138: 149-63.

8 Nilson $\mathrm{K}$. The nature of lymphoid cell lines and their relationship to the virus. In: Epstein MA, Achong BG relationship to the virus. In: Epstein MA, Achong BG
(eds). The Epstein-Barr virus. Berlin: Springer Verlag, 1979: 227-81.

9 Kerr BM, Lear AL, Rowe M, Croom-Carter D, Young LS, Rookes SM, et al. Three transcriptionally distinct forms of Epstein-Barr virus latency in somatic cell hybrids: cell phenotype dependence of virus promoter usage. Virology 1992; 187:189-201

10 Kaye KM, Izumi KM, Kieff E. Epstein-Barr virus latent membrane protein-1 is essential for B-lymphocyte growth transformation. Proc Natl Acad Sci USA 1993;90:9150-4.

11 Wang D, Liebowitz D, Kieff E. An EBV membrane protein expressed in immortalized lymphocytes transforms established rodent cells. Cell 1985;43:831-40.

12 Fåhraeus R, Rymo L, Rhim JS, Klein G. Morphological transformation of human keratinocytes expressing the LMP gene of Epstein-Barr virus. Nature 1990;345:447-9.

13 Dawson CW, Rickinson AB, Young LS. Epstein-Barr virus latent membrane protein inhibits human epithelial cell differentiation. Nature 1990;344:777-80. 
14 Hammerschmidt W, Sugden B, Baichwal VR. The transforming domain alone of the latent membrane protein of Epstein-Barr virus is toxic to cells when expressed at high levels. F Virol 1989;63:2469-75.

15 Moorthy RK, Thorley-Lawson DA. All three domains of the Epstein-Barr virus-encoded latent membrane protein LMP-1 are required for transformation of Rat-1 fibroblasts. F Virol 1993;67:1638-46.

16 Wilson JB, Weinberg W, Johnson R, Yuspa S, Levine AJ. Expression of the BNLF-1 oncogene of Epstein-Barr viru in the skin of transgenic mice induces hyperplasia and aberrant expression of keratin 6. Cell 1990;61:1315-27.

17 Peng $M$, Lundgren E. Transient expression of the Epstein-Barr virus LMP-1 gene in human primary B cells induces cellular activation and DNA synthesis. Oncogene 1992;7:1775-82.

18 Peng $M$, Lundgren E. Transient expression of the Epstein-Barr virus LMP-1 gene in chronic lymphocytic leukemia cells, $T$ cells, and hematopoietic cell lines: Cell-type independent-induction of CD23, CD21 and ICAM-1. Leukemia 1993;7:104-12.

19 Hu LF, Zabarovsky ER, Chen F, Cao SL, Ernberg I, Klein $\mathrm{G}$, et al. Isolation and sequencing of the Epstein-Barr virus BNLF-1 gene (LMP-1) from a Chinese nasopharyngeal carcinoma. f Gen Virol 1991;72:2399-409.

20 Chen ML, Tsai CN, Liang CL, Shu CH, Huang CR, Sulitzeanu D, et al. Cloning and characterization of the latent membrane protein (LMP) of a specific Epstein-Barr virus variant derived from the nasopharyngeal carcinom virus variant derived from the nasopharyngeal carcinom

$21 \mathrm{Hu}$ LF, Chen F, Zheng X, Ernberg I, Cao SL, Christensson $\mathrm{B}$, et al. Clonability and tumorigenicity of human epithelial cells expressing the EBV encoded membrane protein LMP1. Oncogene 1993;8:1575-83.

22 Sandvej K, Peh SC, Andresen B, Pallesen G. Identification of potential hot-spots in the carboxy-terminal part of the Epstein-Barr virus (EBV) BNLF-1 gene in both malignan and benign EBV associated diseases: High frequency of a $30 \mathrm{bp}$ deletion in Malaysian and Danish peripheral T-cell lymphomas. Blood 1994;84:4053-60.

23 Miller WE, Edwards RH, Walling DM, Raab-Traub N. Sequence variation in the Epstein-Barr virus latent Sequence variation in the Epstein-Barr virus

24 Sample J, Kieff EF, Kieff ED. Epstein-Barr virus types 1 and 2 have nearly identical LMP-1 transforming genes. $\mathcal{F} \mathrm{Gen}$ Virol 1994;75:2741-6.

25 Moorthy RK, Thorley-Lawson DA. Biochemical, genetic and functional analysis of the phosphorylation sites on the Epstein-Barr virus-encoded oncogenic latent membrane protein LMP-1. F Virol 1993;67:2637-2645.

$26 \mathrm{Li} \mathrm{SN}$, Chang YS, Liu ST. Effect of a 10 amino acid deletion on the oncogenic activity of latent membrane protein 1 of Epstein-barr virus. Oncogene 1996;12:2129-35.

27 Hansen H, Morling N. Paternity testing with VNTR DNA systems II. Evaluation of 271 cases of disputed paternity with the

28 Morling N, Hansen H. Paternity testing with VNTR DNA systems I. Matching criteria and population frequencies of the VNTR systems D2S44, D5S43, D7S43, D7S21,
D7S22 and D12S11 in Danes. Int F Leg Med 1993;106: 189-96.

29 Nellemann L, Moller A, Morling N. PCR typing of DNA fragments of the short tandem repeat (STR) system
HUMTHO 1 in Danes and Greenland Eskimoes. Forensic Sci Int 1994;68:45-51.

30 Thyman M, Nellemann LJ, Masumba G, Irgens-Møller L Morling N. Analysis of the locus D1S80 by amplified fragments length polymorphism technique (AMRFLP). Frequency distribution in Danes. Intra and inter laboratory reproducibility of the technique. Forensic Sci Int 1993;60: $47-56$.

31 Vindelov LL.Flow microfluorometric analysis of nuclea DNA in cells from solid tumours and cell suspensions. Virchows Arch B Cell Pathol 1977;24:227-42.

32 Sandvej K, Krenacs L, Hamilton-Dutoit S, Rindum J, Pindborg JJ, Pallesen G. Epstein-Barr virus latent and replicative gene expression in oral hairy leukoplakia. Histopathology 1992;20:387-95.

33 Kunimoto M, Tamura S, Tabata T, Yoshie O. One-step typing of Epstein-Barr virus by polymerase chain reaction predominance of type 1 virus in Japan. 7 Gen Virol 1992;73:455-61.

34 Dambaugh T, Hennessy K, Chamnankit L, Kieff E. U2 region of Epstein-Barr virus DNA may encode EpsteinBarr nuclear antigen 2. Proc Natl Acad Sci USA 1984;81:7632-6.

35 Hudson GS, Farrell PJ, Barrell BG. Two related but differentially expressed potential membrane proteins encoded by the EcoRI Dhet region of Epstein-Barr virus B95.8. 7 Virol 1985;53:528-35.

36 Knecht H, Bachmann E, Brousset P, Sandvej K, Nadal D, Bachmann F, et al. Deletion within the LMP-1 oncogene of Epstein-Barr virus are clustered in Hodgkin's disease and Epstein-Barr virus are clustered in Hodgkin's disease and Blood 1993; 82:2937-42.

37 Knecht H, Raphael M, McQuain C, Rothenberger S, Pihan $\mathrm{G}$, Camilleri-Broët $\mathrm{S}$, et al. Deletion variants within the NF- $\kappa B$ activation domain of the LMP-1 oncogene prevail in acquired immunodeficiency syndrome-related large-cel lymphomas and human immunodeficiency virus-negative atypical lymphoproliferetions. Blood 1996;87:876-81.

38 Huen DS, Henderson SA, Croom-Carter D, Rowe M. The Epstein-Barr virus latent membrane protein-1 (LMP-1) mediates activation of NF-kB and cell surface phenotype via two effector regions in its carboxy-terminal cytoplasmatic domain. Oncogene 1995;10:549-60.

39 Trivedi P, Hu LF, Chen F, Christensson B, Masucci MG Klein G. Epstein-Barr virus (EBV)-encoded membrane protein LMP1 from a nasopharyngeal carcinoma is non-immunogenic in a murine model system, in contrast to a B cell-derived homologue. Eur 7 Cancer 1994;30A:84-8.

40 Rowe M, Pilon MP, Huen DS, Hardy R, Croom-Carter D, Lundgren E. Upregulation of BCL-2 by the Epstein-Barr virus latent membrane protein LMP 1: a B-cell-specific responce that is delayed relative to NF- $\mathrm{KB}$ activation and to induction of cell surface markers. F Virol 1994;68:5602-12.

41 Cooper DN, Krawczak M. Human gene mutation. Oxford Bios Scientific Publishers, 1993:179-85. 